Int. J. Electrochem. Sci., 15 (2020) $11112-11122$

International Journal of

ELECTROCHEMICAL

SCIENCE

WWW.electrochemsci.org

\title{
Development and Corrosion Characterization of Ultra-High- Strength Steels
}

\author{
A. Torres-Islas ${ }^{1, *}, F V$ Guerra ${ }^{2}$, A Bedolla-Jacuinde ${ }^{2}$ A. Molina-Ocampo ${ }^{3}$, S. Serna ${ }^{3}$, \\ B. Campillo ${ }^{4}$, and H. Martinez \\ ${ }^{1}$ Facultad de Ciencias Químicas e Ingeniería P.A. Ing. Mecánica, Universidad Autónoma del Estado \\ de Morelos, Av. Universidad 1001, Col. Chamilpa, C.P. 62209, Cuernavaca, Morelos, México. \\ ${ }^{2}$ Instituto de Investigación en Metalúrgia y Materiales, Universidad Michoacana de San Nicolas de \\ Hidalgo Gral.Francisco J. Mugica S/N Felicitas del Rio Morelia Michoacan - 58030, México. \\ ${ }^{3}$ Centro de Investigación en Ingeniería y Ciencias Aplicadas, Universidad Autónoma del Estado de \\ Morelos, Av. Universidad 1001, Col. Chamilpa, C.P. 62209, Cuernavaca, Morelos, México. \\ ${ }^{4}$ UNAM, Facultad de Química/Instituto de Ciencias Físicas, Coyoacan, 04510 México, DF, México \\ ${ }^{5}$ Laboratorio de Espectroscopia, Instituto de Ciencias Físicas, Universidad Nacional Autónoma de \\ México, A.P. 48-3, C.P. \&2210, Cuernavaca - 62210, Morelos México. \\ "E-mail: alvaro.torres@uaem.mx
}

doi: $10.20964 / 2020.11 .22$

Received: 14 July 2020 / Accepted: 22 August 2020 / Published: 30 September 2020

Potentiodynamic polarization and electrochemical impedance spectroscopy measurements were used to investigate the corrosion behavior and mechanical properties of three different quenched and quenched/tempered ultra-high-strength steel alloys in contact with alkaline and acid aqueous solutions. The results are analyzed on the basis of the corrosion potential $E_{\text {corr }}$ and the corrosion current density $I_{\text {corr. }}$ Continuous anodic dissolution is the main type of corrosion driven by a charge-transfer mechanism in all of the investigated steel conditions irrespective of the phases present. The observed solubilities of iron and its oxides and hydroxides respectively agreed with the reactions $\mathrm{Fe}_{2} \mathrm{O}_{3}+\mathrm{H}_{2} \mathrm{O}$ $\rightarrow \mathrm{Fe}(\mathrm{OH})_{2}{ }^{+}$and $2 \mathrm{Fe}^{3+}+3 \mathrm{H}_{2} \mathrm{O} \rightarrow \mathrm{Fe}_{2} \mathrm{O}_{3}+6 \mathrm{H}^{+}$. In addition, the Mo and $\mathrm{V}$ content played important roles in determining the corrosion levels, as did redox reactions and microconstituents present in the various steel phases. The quenched/tempered steel exhibited the best corrosion and mechanical properties.

Keywords: UHSS alloys, Corrosion resistance, Mo and V additions, Alkaline and acid solutions, Mechanical properties.

FULL TEXT 
(C) 2020 The Authors. Published by ESG (www.electrochemsci.org). This article is an open access article distributed under the terms and conditions of the Creative Commons Attribution license (http://creativecommons.org/licenses/by/4.0/). 